THE WORLD BANK ECONOMIC REVIEW, VOL. I6, NO. I I39-I 48

\title{
How Different Is the Efficiency of Public and Private Water Companies in Asia?
}

\author{
Antonio Estache and Martín A. Rossi
}

Several studies have compared the efficiency of publicly and privately owned water utilities and reached conflicting conclusions on the impact of ownership on efficiency. This article provides further evidence by estimating a stochastic cost frontier for a sample of Asian and Pacific regional water companies. The results show that efficiency is not significantly different in private companies than in public ones.

Policymakers in developing countries, eager to resolve the decade-long debate on the gains from privatization of water utilities, are increasingly interested in assessments of the efficiency of public and private water utilities. Most early studies focused on the performance of public and private providers in the United States. Crain and Zardkoohi (1978), estimating a cost function derived from a generalised Cobb-Douglas production function with a dummy variable for ownership, found that publicly owned water utilities in the United States had higher costs than their privately owned counterparts. Feigenbaum and Teeples (1984) used a translog approximation and concluded that they could not reject the hypothesis (at the 5 percent significance level) that the parameters were identical for government and private operation. Byrnes, Grosskopf, and Hayes (1986) measured efficiency directly in terms of a production function and found no evidence that publicly owned utilities are more wasteful or operated with more slack than privately owned utilities. Fox and Hofler (1986) estimated the extent and cost of technical and allocative inefficiency and found no statistical difference in inefficiency for public and private firms, although they did find allocative differences. Overall, these studies leave the impression that there is no convincing evidence of a systematic superiority of one form of ownership over another.

Antonio Estache is with the World Bank Institute, Governance, Regulation, and Finance Division and the European Center for Applied Research in Economics and Statistics, Brussels. His e-mail address is aestache@worldbank.org. Martín A. Rossi is with Universidad Argentina de la Empresa, Economic Regulation Research Centre, Department of Economics, Buenos Aires, and the University of Oxford, Linacre College. His e-mail address is martin.rossi@linacre.ox.ac.uk. The authors are grateful to Ian Alexander, Antonio Alvarez, François Bourguignon, Phil Burns, Ivan Canay, Tim Coelli, Claude Crampes, Severine Dinghem, Lourdes Trujillo, Adele Oliveri, Martín Rodriguez-Pardina, Christian Ruzzier, and two anonymous referees for extensive discussions on the challenges of efficiency measurements and comments on earlier drafts.

(C) 2002 The International Bank for Reconstruction and Development / THE WORLD BANK 
This article provides further evidence for the debate by estimating a stochastic cost frontier using 1995 data from a sample of 50 water companies in 29 Asian and Pacific region countries. Because of conflicting empirical evidence, justification of models and robustness of results are key issues. For that reason, this study applies two approaches to measuring efficiency-error components (EC) and technical efficiency effects (TEE) models-and runs tests for different specifications with those two approaches. The analysis confirms the U.S. results and suggests that efficiency is not significantly different in private and public companies.

\section{The Theoretical Cost Function}

Frontiers are typically classified as production or cost functions, with the nature of the sector determining which function to estimate. Most water utility firms are required to provide services at a preset tariff. In simpler terms, they are required to meet demand and may not chose the level of output to supply. Because output is exogenous, the firm maximizes benefits by minimizing the cost of producing a given level of output. Specification of a cost frontier is thus often the natural choice. ${ }^{1}$

The theoretical specification of the cost function is

$$
C=\mathrm{f}(\mathrm{Y}, \mathbf{Z}, \mathbf{P}) \exp (\varepsilon),
$$

where $C$ is total cost, $\mathrm{Y}$ is the output vector, ${ }^{2} \mathrm{Z}$ is a vector that includes all the relevant exogenous variables needed to allow comparisons across firms, $\mathbf{P}$ is a vector of input prices, and $\varepsilon$ is the error term.

The systematic part of the model is the cost frontier, which determines the minimum cost achievable for a given set of outputs, input prices, and control variables. The error term can be decomposed in two parts:

$$
\varepsilon_{i}=u_{i}+v_{i}
$$

where $u_{i} \geq 0$ and $v_{i}$ is not constrained. The $v_{i}$ component captures the effects (for firm $i$ ) of the stochastic noise and is assumed to be independent and identically distributed following a normal distribution $N\left(0, \sigma^{2}{ }_{v}\right)$. This component accounts for measurement error and other random factors, such as effects of weather and strikes, as well as misspecifications in the estimated cost function. The $u_{i}$ component represents the cost inefficiency and is assumed to be distributed independently from $v_{i}$ and the regressors. Various distributions have been suggested for this term: half-normal (Aigner, Lovell, and Schmidt 1977), gamma (Greene 1990), and exponential (Meeusen and van de Broeck 1977). The half-normal

1. Nevertheless, utilities frequently do limit the number of customers through the use of two-part tariffs or rationing.

2. Another advantage of the cost frontier over the production frontier is that it deals better with multiple outputs. 
distribution is the most commonly used in empirical studies and implies that the majority of the firms are almost efficient. To avoid imposing such an a priori distribution of the inefficiency term, the more flexible truncated normal was adopted (Stevenson 1980), a generalization of the half-normal obtained by truncating to zero a normal distribution with median $\mu$ and variance $\sigma^{2}{ }_{u}$. Setting $\mu$ to zero reduces to the traditional half-normal model. Therefore, the null hypothesis Ho: $\mu=0$ will be tested.

When the error term enters multiplicatively in the cost function (additively after logs where taken), the level of the cost efficiency or overall economic efficiency of the $i$ th firm is

$$
E F_{i}=\exp \left(-u_{i}\right)
$$

The problem is that the $u_{i}$ term is unobservable. Battese and Coelli (1988) show that the best predictor of $\exp \left(-u_{i}\right)$ is obtained by using the conditional expectation

$$
E\left[\exp \left(-u_{i}\right) \mid \varepsilon_{i}\right]=\left\{\left[1-\Phi\left(\sigma_{A}-\gamma \varepsilon_{i} / \sigma_{A}\right)\right] /\left[1-\Phi\left(-\gamma \varepsilon_{i} / \sigma_{A}\right)\right]\right\} * \exp \left(-\gamma \varepsilon_{i}+\sigma^{2}{ }_{A} / 2\right),
$$

where $\Phi($.$) is the distribution function of the standard normal random variable.$ Following the parameterization proposed by Battese and Corra (1977), $\sigma_{\nu}{ }^{2}$ and $\sigma_{u}{ }^{2}$ are replaced with $\sigma^{2}=\sigma_{v}{ }^{2}+\sigma_{u}{ }^{2}, \gamma=\sigma_{u}{ }^{2} /\left(\sigma_{v}{ }^{2}+\sigma_{u}{ }^{2}\right)$, and $\sigma_{A}=\left[\gamma(1-\gamma) \sigma^{2}\right]^{1 / 2}$. The parameter $\gamma$ must lie between 0 and 1 , with 0 indicating that the deviations from the frontier are due entirely to noise, and 1 indicating that all deviations are due to inefficiency. This specification allows testing the null hypothesis that there are no inefficiency effects in the model, $\mathrm{H}_{0}: \gamma=0$, against the alternative hypothesis, $\mathrm{H}_{1}: \gamma>0$.

FRONTIER version 4.1 (Coelli 1996) is used to obtain the maximum likelihood $(\mathrm{ML})$ estimates of the parameters of this model and the efficiency measures.

\section{Data And Estimation}

The cost frontier for the Asian water utilities was estimated from a database published by the Asian Development Bank (McIntosh and Yñiguez 1997). The sample covers 50 firms surveyed in 1995 in 19 countries: Bangladesh (2 firms), Bhutan (1), Cambodia (1), China (5, including Hong Kong and Taiwan), Cook Islands (1), Fiji (1), India (4), Indonesia (3), Kazakhstan (1), Republic of Korea (2), Kyrgyz Republic (1), Lao People's Democratic Republic (1), Malaysia (3), Maldives (1), Mongolia (1), Myanmar (2), Nepal (1), Pakistan (3), Papua New Guinea (1), the Philippines (3), Singapore (1), the Solomon Islands (1), Sri Lanka (1), Thailand (3), Tonga (1), Uzbekistan (1), Vanuatu (1), Vietnam (2), and Samoa (1). ${ }^{3}$

The data have the advantage of providing comparable information for all the sample companies, but they have limitations. They cover just one year, and they

3. The 50 Asian water companies were selected jointly by representatives of utilities and the Asian Development Bank (АDB). АDB recruited domestic consultants to assist firms in responding to the questionnaire. 
are too sparse to support complete analysis of each company. Because they contain no information on the asset base, it is difficult to assess whether operational costs are consistent with the maintenance requirements of the assets. This is an important issue for regulated firms subject to price or revenue caps because their chief cost-cutting options for meeting caps or other restrictions are to reduce the quality of service or to cut back on maintenance. The relevance of the unavailability of the asset data for the comparison of public and private provision is uncertain. Even so, using the cost data to compare the performance of firms in the sample allows for testing of the robustness of earlier results of studies comparing public and private firms in developing countries.

The data cover operational costs (COST, in thousands of U.S. dollars) ${ }^{4}$ annual salary (SALAR, estimated as the ratio of total salary cost to the number of workers), number of clients (CLIEN, in thousands), daily production (PROD, in cubic meters per day), number of connections (CONE), population density in the area served (DENS, in people per square kilometer), percentage of water from surface sources (ASUP), number of hours of water availability per day (QUALI, in h), percentage of metered connections (METER), and a set of qualitative variables on the type of treatment used: chlorination (DUMCLO, with a value of 1 when the treatment is chlorination and 0 otherwise) and desalination (DUMDES; in fact, only one company uses desalinization).

The estimated function is in line with practice in previous studies (see Stewart 1993, Crampes, Diette, and Estache 1997, Price 1993, Byrnes, Grosskopf, and Hayes, 1986, Fox and Hofler 1986, and Bhattacharyya, Harris, and Rangesan 1995). However, because the only input price available was for labor, an ad hoc cost function was estimated. ${ }^{5}$ The dependent variable is operational costs, which include expenditures for personnel, power, parts, materials, and bulk purchase of water in some cases. ${ }^{6}$ Included as the main cost drivers are average salary (proxy of the main input price), number of clients, daily production and number of connections (proxies of outputs), population density, percentage of water from surface sources, percentage of metered connections, quality, and two dummy variables that account for differences in the type of treatment used (environmental variables).

One advantage of this methodology is that it allows for the inclusion of environmental variables in the model specification—variables that may affect the performance of the firm but are not entirely under its control. Their inclusion ensures that the various operators of an activity are effectively comparable. Population

4. To make data comparable, gross COST data in local currency were converted into U.S. dollars at the rate of exchange as of July 1, 1997, using market rates from the New York Foreign Exchange, rates from the country's central bank, or book rates provided by the International Monetary Fund.

5. Estimation of a cost function requires data on input prices, including capital. However, this information is difficult to obtain (see, for example, Huettner and Landon 1977, for the electricity distribution sector). The usual solution is to formulate an arbitrary cost function, without including the price of the capital input.

6. The average share of labor in operational cost is 35 percent, with a standard error of 20 percent. 
density, for instance, plays an important role in defining the network infrastructure, especially in regulated firms that are obliged to serve a specific geographical area. The percentage of water from surface sources is included as a control variable because the costs associated with drawing water very much depend on the water input source. The percentage of metered connections is included as a regressor because the administrative cost is higher than it is for the flat-rate system (Bhattacharyya, Harris, and Rangesan 1995). Hours of water availability are included because that can affect costs even after controlling for outputs.

Twenty-two of the 50 utilities have some form of private sector participation. Major private sector management (concession) is under way in the Philippines, Vanuatu, Maldives, and the Solomon Islands. Other types of private sector participation include billing and collection, leak repair, meter reading, source development, production, and pumping (McIntosh and Yñiguez 1997). Three dummy variables are included to account for this heterogeneity: a dummy concession (DUMCON, with a value of 1 if the firm is a concession and 0 otherwise), a dummy administration $(D U M B C$, with a value of 1 if the private sector is involved in billing, collection, leak repair, or meter reading and 0 otherwise), and a dummy for other private sector participation (DUMOP). The basis for comparison will be public sector performance. The basic statistics are summarized in table 1 .

Because the quality of the estimates of the frontier and efficiency measures depend on the accuracy of the specification of the functional form, the CobbDouglas specification was tested. A translog cost function, a more flexible form, was not estimated because the inclusion of the second-order and cross terms would leave the model with very few degrees of freedom. To account for variable returns to scale, the models were run with quadratic terms in output alone and in labor price and output variables. In neither case were the results for the included variables statistically significant. A likelihood ratio test was performed, and the null of the Cobb-Douglas specification could not be rejected. ${ }^{7}$ Therefore, a Cobb-Douglas cost function was estimated. The initial model is as follows.

$$
\begin{aligned}
\ln C O S T= & \alpha+\beta \ln S A L A R+\omega_{1} \ln C L I E N+\omega_{2} \ln C O N E+\omega_{3} \ln P R O D \\
& +\pi_{1} \ln \text { DENS }+\pi_{2} \text { ASUP }+\pi_{3} \text { QUALI }+\pi_{4} \text { METER }+\pi_{5} \text { DUMDES } \\
& +\pi_{6} \text { DUMCLO }+\pi_{7} \text { DUMCON }+\pi_{8} \text { DUMBC }+\pi_{9} \text { DUMOP }
\end{aligned}
$$

The estimated value of $\mu$ in the EC model was 0.09 , with a standard error of 1.14 . A likelihood ratio test was performed, and since the null hypothesis $(\mu=0)$ could not be rejected, the estimation assumed a half-normal distribution.

For the ordinary least squares (OLS), corrected ordinary least squares, ${ }^{8}$ and ML estimates of the EC model, the signs of the coefficients are as expected (table 2). The labor input has a positive and significant sign, as do connections and clients. The other product (daily production) has the expected positive sign but is not

7. A RESET test (second power) showed no evidence of omitted variables in the model.

8. OLs plus a change in the intercept. 
Table 1. Values of Key Variables for 50 Sample Firms

\begin{tabular}{lcr}
\hline Variable & Average & $S D$ \\
\hline COST (thousands of us\$) & 29,372 & 67,721 \\
SALAR (dollars) & 5,042 & 8,619 \\
CLIEN (thousands) & 2,453 & 2,945 \\
PROD (m³/day) & 935 & 1,254 \\
CONE (number) & 416 & 548 \\
DENS (people per $\mathrm{km}^{2}$ ) & 16,587 & 33,479 \\
ASUP (\%) & 0.67 & 0.41 \\
METER (\%) & 0.74 & 0.39 \\
QUALI (hours of water availability per day) & 18.98 & 6.85 \\
\hline
\end{tabular}

Source: McIntosh and Yñiguez (1997).

significant. ${ }^{9}$ An improvement in quality increases costs, as does an increase in the proportion of metered clients. Population density has a negative and significant sign, suggesting that it is cheaper to serve more densely populated areas. The proportion of water from the surface is not significant. The dummy variable for desalinization is positive but not significant. The signs on the concession dummy variable and the other private sector participation dummy variable are positive but not significant. Finally, the sign of the dummy administration is negative but not significant.

In the extreme case, where $\sigma_{u}^{2}=0$ (the ratio of the variance of noise to the total residual variance is equal to 1 ), the $\mathrm{ML}$ and ols estimates are the same, because the composed errors follow a normal distribution. The ML and oLs estimates in table 2 are quite close, which can be explained by the low value of $\gamma$ (which is not statistically significantly different from zero) or, analogously, by the high (0.60) ratio of the variance of noise to the total residual variance. ${ }^{10}$ These results seem to suggest that ols is the appropriate model (i.e., there is no need to estimate a frontier as all departures from the cost function are due to noise); with no frontier necessary, all observations can be considered equally efficient, which supports the hypothesis of no differences in cost efficiencies between public and private operators.

To determine the robustness of the results, a second model was estimated in which the inefficiency effects are expressed as a function of the ownership dummy variables. This TEE model, as proposed by Battese and Coelli (1995), is similar to the EC model except that the efficiency error has a mean of $m_{i}$ instead of 0 , where $m_{i}=\delta x_{i}$ is a contemporaneous auxiliary regression such that $\mathbf{x}_{i}$ is a $p \times 1$ vector of variables that may influence the efficiency of the firm and $\delta$ is a $1 \times p$ vector of parameters to be estimated simultaneously with the parameters $\alpha, \beta, \omega$, and $\pi .{ }^{11}$

9. When the model was run without CONE, the main conclusions were unaffected, but the $t$-value of $P R O D$ increased.

10. Estimated as $\sigma_{v}^{2} /\left(\sigma_{v}^{2}+\sigma_{u}^{2} \pi /[\pi-2]\right)$ or $1-(\gamma /[\gamma+(1-\gamma) \pi /(\pi-2)])$.

11. If $x_{i}$ contains the value 1 and no other variable, then the model reduces to the truncated normal proposed by Stevenson (1980) and shown here. 
TABLe 2. Results for the Error Components Model

\begin{tabular}{lrcccc}
\hline Variable & \multicolumn{2}{c}{ OLS } & Corrected OLS & \multicolumn{2}{c}{ ML } \\
\hline Constant & 0.495 & $(0.53)$ & 0.280 & 0.139 & $(0.16)$ \\
$\ln ($ SALAR $)$ & 0.293 & $(6.06)$ & 0.293 & 0.297 & $(6.97)$ \\
$\ln ($ CLIEN $)$ & 0.671 & $(3.63)$ & 0.671 & 0.700 & $(3.82)$ \\
$\ln ($ CONE $)$ & 0.269 & $(3.95)$ & 0.269 & 0.285 & $(4.13)$ \\
$\ln ($ PROD $)$ & 0.080 & $(0.45)$ & 0.080 & 0.044 & $(0.25)$ \\
$\ln ($ DENS $)$ & -0.139 & $(-1.65)$ & -0.139 & -0.148 & $(-1.88)$ \\
ASUP & 0.116 & $(0.46)$ & 0.116 & 0.106 & $(0.49)$ \\
QUALI & 0.029 & $(1.99)$ & 0.029 & 0.029 & $(2.32)$ \\
METER & 0.320 & $(1.51)$ & 0.320 & 0.293 & $(1.51)$ \\
DUMDES & 0.577 & $(0.81)$ & 0.577 & 0.539 & $(0.88)$ \\
DUMCLO & 0.213 & $(1.01)$ & 0.213 & 0.195 & $(1.08)$ \\
DUMCON & 0.002 & $(0.008)$ & 0.002 & 0.044 & $(0.17)$ \\
DUMBC & -0.092 & $(-0.49)$ & -0.092 & -0.067 & $(-0.40)$ \\
DUMOP & 0.195 & $(1.01)$ & 0.195 & 0.196 & $(1.18)$ \\
$\gamma$ & & 0.420 & 0.65 & $(1.15)$ & \\
Log-likelihood & -19.42 & & & -19.34 & \\
\hline
\end{tabular}

Note: The dependent variable is the log of operational cost $(\ln C O s T)$. The numbers in parentheses are $t$-statistics.

Source: Authors' calculations based on data from McIntosh and Yñiguez (1997).

The results are similar to those for the EC model. ${ }^{12}$ Salary, percentage of metered clients, and hours of water availability all have a positive and significant effect on costs (table 3). As in the EC model, population density has a negative and significant sign and percentage of water from surface sources has a positive but not significant effect. The only difference between the two specifications is on the private-public question, because the concession dummy variable has a negative sign, although, as in the EC model, it is not significant.

Average efficiency is 1.39 in the EC model and 1.44 in the TEE model. The ML estimates (both the EC and TEE models) suggest that the differences between private and public operators are not significant, and similar results arise from the oLs estimates. ${ }^{13}$

\section{Where Do We Go from Here?}

The results discussed here confirm the very cloudy impression emerging from the U.S. experience and do not provide strong evidence that private providers are globally more efficient than public operators. However, the results highlight

12. With a TEE model including a constant term in the inefficiency term, the main result relating to the public-private issues was unaffected.

13. The TEE and EC models differ in that the EC model allows for different intercepts for the different ownership categories whereas the TEE model assumes the same intercept. Hence the cost efficiency scores from the TEE model are gross because they include the ownership effect while the scores from the EC model are net of this effect (see Coelli, Perelman, and Trujillo 1999 for more on net and gross efficiency). 
TABle 3. Results for the Technical Efficiency Effects Model

\begin{tabular}{lrrcrr}
\hline Variable & \multicolumn{2}{c}{ OLS } & Corrected OLS & \multicolumn{2}{c}{ ML } \\
\hline Constant & 0.609 & $(0.71)$ & 0.330 & -0.113 & $(-0.14)$ \\
$\ln ($ SALAR $)$ & 0.294 & $(6.72)$ & 0.294 & 0.303 & $(6.94)$ \\
$\ln ($ CLIEN) & 0.708 & $(3.97)$ & 0.708 & 0.668 & $(3.30)$ \\
$\operatorname{Ln}($ CONE $)$ & 0.269 & $(4.48)$ & 0.269 & 0.305 & $(4.59)$ \\
$\ln ($ PROD $)$ & 0.050 & $(0.29)$ & 0.050 & 0.054 & $(0.30)$ \\
$\ln ($ DENS $)$ & -0.161 & $(-2.05)$ & -0.161 & -0.127 & $(-1.53)$ \\
ASUP & 0.105 & $(0.43)$ & 0.105 & 0.150 & $(0.74)$ \\
QUALI & 0.031 & $(2.26)$ & 0.031 & 0.029 & $(2.24)$ \\
METER & 0.255 & $(1.32)$ & 0.255 & 0.372 & $(1.66)$ \\
DUMDES & 0.537 & $(0.88)$ & 0.537 & 0.632 & $(0.11)$ \\
DUMCLO & 0.171 & $(0.87)$ & 0.171 & 0.238 & $(1.19)$ \\
$\delta_{2}($ DUMCON $)$ & & & & -0.290 & $(-0.24)$ \\
$\delta_{3}($ DUMBC) & & & & -0.955 & $(-0.74)$ \\
$\delta_{3}($ DUMOP $)$ & & & 0.580 & 0.309 & $(0.98)$ \\
$\gamma$ & & & & -18.80 & $(2.28)$ \\
Log-likelihood & -20.63 & & & & \\
\hline
\end{tabular}

Note: The dependent variable is the $\log$ of operational cost $(\ln C O S T)$. The numbers in parentheses are $t$-statistics.

Source: Authors' calculations based on data from McIntosh and Yñiguez (1997).

the difficulty of measuring efficiency, reflecting a long tradition of lack of concern for efficiency among regulators in developing countries. This is changing, however. One of the main regulatory adjustments over the last decade has been the recognition that efficiency does matter, a feeling that is spreading as privatization takes hold around the world. Many regulators have switched from rateof-return regulation to price or revenue-cap regulation to increase the incentive for firms to minimize costs and to ensure that consumers eventually benefit from these cost reductions.

This means that costs need to be measured much more precisely than they were for the ADв database (McIntosh and Yñiguez 1997). Indeed, if any cost reductions are expected to result from private operation of the sector, they should be associated with efficiency gains rather than quality reductions. Both have to be measured if cost differences-or the lack thereof-across firms are to be explained correctly. ${ }^{14}$ This alone explains why efficiency measures are no longer a side show as they were under rate-of-return regulation. The data here do not allow for testing of tradeoffs between efficiency gains and quality reductions.

A related regulatory challenge is how to document the fact that a firm's efficiency gains can come from two different sources. Gains can come from shifts in the frontiers reflecting efficiency gains at the sectoral level. But efficiency gains at the firm level can also reflect a catching-up effect. These are the gains 
to be made by a firm not yet on the frontier. Public firms that have to compete with new private entrants who enjoy the latest technology will often be expected to play catch-up or die. These firms should be able to achieve not only the industry gain but also specific gains to offset firm-specific inefficiencies. This catch-up effect is one of the expected benefits to consumers of yardstick competition if regulators can ensure that quality is not the adjustment variable for the least cost efficient firms. Yardstick competition-even implicit, as a consequence of studies of this kind that generate results forcing comparisonsshould minimize the scope for major differences between public and private providers. In the end, the inconclusiveness of the comparison of efficiency in public and private water utilities may simply reflect the fact that competition matters more than ownership.

\section{REFERENCES}

Aigner, D., C. Lovell, and P. Schmidt. 1977. "Formulation and Estimation of Stochastic Frontier Production Function Models." Journal of Econometrics 6(1):21-37.

Battese, G., and T. Coelli. 1988. "Prediction of Firm-Level Technical Efficiencies with a Generalized Frontier Production Function and Panel Data." Journal of Econometrics 38:387-99.

- 1995. "A Model for Technical Inefficiency Effects in a Stochastic Frontier Production Function for Panel Data." Empirical Economics 20:325-32.

Battese, G., and G. Corra. 1977. "Estimation of a Production Frontier Model: With Application to the Pastoral Zone of Eastern Australia." Australian Journal of Agricultural Economics 21(3):169-79.

Bhattacharyya, A., T. Harris and N. Rangesan. 1995. "Allocative Efficiency of Rural Nevada Water Systems: A Hedonic Shadow Cost Function Approach.” Journal of Regional Science 35(3):485-501.

Byrnes, P., S. Grosskopf, and K. Hayes. 1986. "Efficiency and Ownership: Further Evidence." Review of Economics and Statistics 68(2):337-41.

Coelli, T. 1996. "A Guide to FRONTIER, Version 4.1: A Computer Program for Stochastic Frontier Production and Cost Function Estimation." CEPA Working Paper 96/ 07, University of New England, Centre for Efficiency and Productivity Analysis, Sydney.

Coelli, T., S. Perelman, and E. Romano. 1999. "Accounting for Environmental Influences in Stochastic Frontier Models: With Application to International Airlines." Journal of Productivity Analysis 11:251-73.

Coelli, T., A. Estache, S. Perelman, and L. Trujillo. 2001. "A Primer on Efficiency Measurement for Utilities and Transport Regulators.” The World Bank Institute, mimeo.

Crain, W., and A. Zardkoohi. 1978. "A Test of the Property Rights Theory of the Firm: Water Utilities in the United States." Journal of Law and Economics 21:395-408.

Crampes, C., N. Diette, and A. Estache. 1997. "What Could Regulators Learn from Yardstick Competition? Lessons for Brazil's Water and Sanitation Sector.” World Bank, Washington, D.C.

Feigenbaum, S., and R. Teeples. 1984. "Public versus Private Water Delivery: A Hedonic Cost Approach." Review of Economics and Statistics 65:672-78. 
Fox, W., and R. Hofler. 1986. "Using Homothetic Composed Error Frontiers to Measure Water Utility Efficiency.” Southern Economic Journal 53(2):461-77.

Greene, W. 1990. “A Gamma-Distributed Stochastic Frontier Model.” Journal of Econometrics 46(1/2):141-63.

Huettner, D., and Landon, J. 1977. "Electric Utilities: Scale Economies and Diseconomies." Southern Economic Journal 44:883-912.

McIntosh, A., and C. Yñiguez. 1997. Second Water Utilities Data Book: Asian and Pacific Region. Manila: Asian Development Bank.

Meeusen, W., and J. van de Broeck. 1977. "Efficiency Estimation from Cobb-Douglas Production Functions with Composed Error." International Economic Review 18(2):435-84.

Price, J. 1993. "Comparing the Cost of Water Delivered. Initial Research into the Impact of Operating Conditions on Company Costs." Ofwat Research Paper 1, Office of Water Services, Birmingham.

Stevenson, R. 1980. "Likelihood Functions for Generalized Stochastic Frontier Estimation." Journal of Econometrics 13(1):57-66.

Stewart, M. 1993. "Modeling Water Costs 1992-93: Further Research into the Impact of Operating Conditions on Company Costs." Ofwat Research Paper 2, Office of Water Services, Birmingham. 